\title{
REVIEW
}

\section{Pharmacological management of tetanus: an evidence-based review}

\author{
Chaturaka Rodrigo $^{1 *}$, Deepika Fernando ${ }^{1,2}$ and Senaka Rajapakse
}

\begin{abstract}
Tetanus is becoming rarer in both industrialized and developing nations due to an effective vaccination program. In 2010, the World Health Organization estimated there was a $93 \%$ reduction in newborns dying from tetanus worldwide, compared to the situation in the late 1980s. Due to its rarity, many diagnostic delays occur as physicians may not consider the diagnosis until the manifestations become overt. Without timely diagnosis and proper treatment, severe tetanus is fatal (mortality is also influenced by the comorbidities of the patient). The principles of treating tetanus are: reducing muscle spasms, rigidity and autonomic instability (with ventilatory support when necessary); neutralization of tetanus toxin with human antitetanus immunoglobulin or equine antitetanus sera; wound debridement; and administration of antibiotics to eradicate locally proliferating bacteria at the wound site. It is difficult to conduct trials on different treatment modalities in tetanus due to both logistical and ethical reasons. However, it is imperative that physicians are aware of the best evidence-based treatment strategies currently available to improve the outcome of patients. This review concentrates on analyzing the current evidence on the pharmacological management of tetanus.
\end{abstract}

\section{Introduction}

Tetanus is caused by the obligatory anaerobic Grampositive bacillus Clostridium tetani. Despite a global reduction in its incidence, the condition is still a threat in many developing countries [1-4]. Though a rarity, it is still reported in developed nations, especially in the farming community [5]. The impact in low prevalence areas is exaggerated by the fact that physicians may not

\footnotetext{
* Correspondence: chaturaka.rodrigo@gmail.com

${ }^{1}$ Tropical Medicine Research Unit, Department of Clinical Medicine, Faculty of Medicine, University of Colombo, 25 Kynsey Road, Colombo 08, Sri Lanka Full list of author information is available at the end of the article
}

recognize tetanus due to unfamiliarity [6]. Failure in timely recognition and initiation of treatment can be fatal. According to World Health Organization (WHO) data, approximately 9,600 cases of tetanus were reported globally in 2010 [7]. This is a sharp drop from the annual incidence figures in 1980, which exceeded 110,000. Tetanus was a major killer in neonates and children a few decades ago, but the numbers have reduced markedly with effective vaccination programs in many countries. In 2010, the World Health Organization estimated a 93\% reduction in newborns dying from tetanus worldwide compared to the situation in the late 1980s [8]. Most countries now boast more than $90 \%$ coverage of infants in immunization programs [7]. However, it is difficult to eradicate the disease due to the abundance of tetanus bacterial spores in the environment. The goal is to work towards elimination of tetanus through vaccination. In 1999, 57 countries had failed to eliminate maternal and neonatal tetanus but, by 2013, 31 of those countries had managed to reach elimination status [9].

The classical presentation of tetanus seen in patients begins with trismus or 'locked jaw' due to spasms of the masseter. Rigidity then spreads down the arms and trunks over the next 1 to 2 days, progressing to generalized muscle rigidity, stiffness, reflex spasms, opisthotonus and dysphagia. Even minute sensory stimulation can precipitate prolonged spasms. The generalized spasms are also accompanied by autonomic disturbances, such as swings in blood pressure, arrhythmias, hyperpyrexia and sweating. Exhaustion, autonomic disturbances, and complications from muscle spasms (for example, asphyxiation, pneumonia, rhabdomyolysis, pulmonary emboli) can contribute to the high fatality rates observed in severe tetanus [10].

Probably the most successful intervention against tetanus in history is its prevention by means of an effective vaccine; the success of vaccination has led to a dramatic fall in the incidence of tetanus [7]. However, treatment of this disease is less effective, with high rates of mortality reported from case series around the world. Still, 
improvements in ICU facilities, closer monitoring and certain pharmacological interventions have increased survival rates. Many new and experimental therapeutic approaches for managing patients with tetanus have been explored in recent decades. This review addresses the timely need of summarizing the evidence base for currently used and experimental pharmacological therapy in treating tetanus.

\section{Methods}

This systematic narrative review was synthesized by searching PUBMED with the keywords 'tetanus' in title and 'management' in abstract, which resulted in 271 hits. The search was repeated again with 'tetanus' in title and 'treatment' in abstract with 1,210 hits. The keywords were selected to find core articles that would address the management of tetanus. The time limit for the search was from 1992 to 2012 to include more recent opinions on the subject. The software Endnote X3 (Thomson Reuters, Carlsbad, CA, USA) was used to filter articles. Bibliographies of cited literature were also searched. All abstracts were read independently by two authors, and key articles were identified based on a consensus among all authors.

\section{Results/review}

We selected 67 articles for the final synthesis based on relevance to the topic. These included five retrospective studies, 13 prospective studies/case series, nine randomized trials and five systematic reviews. In addition, narrative reviews, opinion papers and relevant case reports were also scrutinized.

Treatment in tetanus is based on several key principles: a) sedation and paralysis to control the progressive spasms and autonomic dysfunction and to avoid exhaustion; b) surgical debridement and antibiotic treatment for the source of infection; c) neutralization of the circulating toxin; and c) supportive care in an ICU. Deep sedation and paralysis with artificial ventilation in an ICU has its drawbacks. The patient may require prolonged periods of intubation and ventilation, increasing vulnerability to ventilator-associated pneumonia, tracheal stenosis, difficulty in weaning and adult respiratory distress syndrome. Similarly, facilities for prolonged periods of ventilation are limited in many developing countries where tetanus still poses a major threat. Therefore, many clinicians have explored the possibility of using pharmacological means to control the spasms without the need for heavy sedation and artificial ventilation. Several options that have been explored include intravenous magnesium sulfate, baclofen and dantrolene.

\section{Controlling muscle spasms and autonomic dysfunction}

The 'routine' practice in treating patients with tetanus includes heavy sedation and paralysis with neuromuscular blockade by muscle relaxants supported by artificial ventilation. The rates of survival with this practice have improved over the years with better ICU facilities and ventilatory options, as demonstrated by a comparative analysis of two case series in Australia [11]. Sedatives used vary from benzodiazepines such as midazolam and diazepam to anesthetic agents such as propofol [12-14]. Phenothiazines such as chlorpromazine are also used for sedation in resource-limited settings. Neuromuscular blockers used include pipecuronium, vecuronium and pancuronium.

\section{Benzodiazepines}

Benzodiazepines are the standard therapy for controlling muscle spasms in tetanus and have gained popularity over other agents due to their combined muscle relaxant, anticonvulsant, sedative and anxiolytic effects, which can be quite useful in managing a patient with tetanus. The most popular option with regard to benzodiazepines is diazepam, which is cheap and available in many resource-limited settings where tetanus is a significant public health problem. There are not many randomized clinical trials on diazepam for an obvious reason; it is established therapy in tetanus and depriving a patient of treatment with benzodiazepines in severe tetanus is unethical. Many early studies established the role of diazepam as a useful agent in tetanus [15,16] and some of these compared the role of diazepam against other sedatives available at that time, such as chlorpromazine and phenobarbitone. Diazepam modulates GABA-A transmission and increases presynaptic inhibition. In a Cochrane review to assess the relative efficacy of diazepam in the treatment of tetanus in adults and children, Okoromah and Lesi [17] concluded that using diazepam was associated with better survival rate in children when compared to a combination of phenobarbitone and chlorpromazine (relative risk for death 0.36 , 95\% confidence interval 0.15 to 0.86 ; risk difference -0.22 , $95 \%$ confidence interval -0.38 to -0.06 ). However, despite searching for all randomized and quasi randomized trials in many databases, they only managed to find two trials matching the inclusion criteria $(\mathrm{n}=134)$ demonstrating the paucity of evidence for pharmacological therapy in tetanus.

The use of midazolam, a relatively short acting benzodiazepine, is a theoretically better option than diazepam. However, there is limited evidence on the use of this drug and in most occasions its use in the medical literature is described in case reports and case series in conjunction with other muscle relaxants, anesthetic agents and magnesium sulfate [18-21]. There is no head-to- 
head comparison of midazolam with diazepam and its efficacy is difficult to differentiate from other concurrently used drugs $[22,23]$. The same limitations hold true for lorazepam $[24,25]$.

Despite the lack of evidence (which is partly due to obvious ethical issues in designing trials), benzodiazepines remain the backbone of treatment regimens for tetanus. The dosing is adjusted according to the clinical response of the patient, but large doses may be needed in severe cases (there is a risk of precipitating metabolic acidosis due to the preservative propylene glycol when using large doses of diazepam). Long acting drugs such as diazepam are lipid soluble and hence have a large volume of distribution and may lead to a prolonged recovery when the doses are tailed off. Other treatment options, described below, are mostly compared against benzodiazepines and ironically have a larger evidence base for their use in the literature.

\section{Intravenous magnesium sulfate}

Magnesium sulfate is a widely accepted therapy for controlling eclampsia in obstetric practice. It functions as a physiological antagonist of calcium at the cellular level causing vasodilatation, presynaptic neuromuscular blockade and prevention of catecholamine release [26]. It also has anticonvulsant properties [27]. A safe serum therapeutic range of 2 to $4 \mathrm{mmol} / \mathrm{l}$ has been established for patients with eclampsia [28].

Magnesium treatment to control tetanic spasms has been recorded in the medical literature for a long time but its use in more recent times has been established since the 1980s with the emergence of case reports of the successful control of tetanic spasms with continuous infusions $[29,30]$. However, the first case series involving a comparatively large number of patients $(n=40)$ was reported by Attygalle and Rodrigo in 2002 [31]. Following a pilot study in which eight patients were successfully managed with intravenous (IV) magnesium sulfate over a period of 1 year with minimal need for ventilatory support [32], they conducted a prospective observational study to observe the effects of magnesium sulfate as first-line therapy. Of the 40 patients assessed, 36 had spasms. Magnesium sulfate therapy was initiated with a loading dose of 75 to $80 \mathrm{mg} / \mathrm{kg}$ in 30 minutes and continued at a rate of $2 \mathrm{~g} /$ hour for patients aged under 60 years and $1 \mathrm{~g} /$ hour for patients aged over 60 years. Increments of infusion rates were made at 6 hourly intervals depending on patient comfort and degree of spasms. The clinical evidence of magnesium toxicity was gauged by loss of patellar reflex, hypocalcemia, excessive sedation, and respiratory and cardiovascular depression. The authors demonstrated that the spasms were effectively controlled in many patients (to allow physiotherapy, oral care and swallowing) at a serum magnesium concentration of 2 to $4 \mathrm{mmol} / \mathrm{l}$. The lowest calcium level reported in this series was $1.6 \mathrm{mmol} / \mathrm{l}$, but it reverted to normal range within 48 hours of stopping magnesium. They also demonstrated that $23(57 \%)$ patients did not require any ventilatory support throughout their illness, while in those who required ventilation, older age, magnesium toxicity itself and pre-existing respiratory disease, such as chronic obstructive airway disease, might have played a contributory role rather than tetanus itself. The overall mortality was $12 \%$ (five deaths, all in patients aged over 60 years due to infective causes and gastric hemorrhage) and the mean overall ICU stay was 23.1 (standard deviation (SD) \pm 7.6 ) days. The total mean duration of IV magnesium sulfate therapy in survivors was 18.2 ( $\mathrm{SD} \pm 5.9$ ) days. The authors concluded that the mortality rates and duration of ICU stay in this series was better compared to contemporary figures, and recommended IV magnesium sulfate as the first-line therapy to control tetanic spasms.

Mathew and colleagues [27], in a case series in Chandigarh, India $(\mathrm{n}=33)$, also demonstrated a clinical benefit of IV magnesium sulfate infusion for controlling spasms at a loading dose and incremental doses similar to those in the study above. However, they noted that magnesium as sole therapy was adequate in only six patients who had a milder form of the illness (severity grading of I or II according to the Ablett scoring system). Those with a grade of III and IV developed further spasms and autonomic instability while being on adequate doses of magnesium and required additional pharmacological and ventilatory support. The earlier series did not report severity grading according to the Ablett scoring system (which is based on clinical features) and a comparison is not therefore possible. The mean duration of ICU stay was comparable in the two studies but the mortality rate was higher in the second series $(23 \%)$, reflecting a series with more severe disease. Mathew and colleagues concluded that the beneficial effects of magnesium are obvious in tetanus, but it may be inadequate as sole therapy in patients with severe disease.

A randomized placebo-controlled trial with regard to magnesium in tetanus was conducted by Thwaites and colleagues in Vietnam [21]. In this trial, 97 and 98 patients with tetanus of comparable severity (independently verified with three different scoring systems) were allocated to receive either magnesium sulfate or placebo while receiving standard therapy (high dose diazepam for sedation replaced with midazolam as required, neuromuscular junction blockade and respiratory support when necessary). The loading dose used was less than that used in the case series above but the hourly infusion rates were comparable. However, dose titration to control symptoms was not possible due to the blinding 
in the study. The primary outcome assessed was the need for ventilatory support within the first 7 days of magnesium therapy, which showed no difference between groups (there was no difference in this regard even when the analysis was extended to cover the entire hospital stay). There was also no effect on total duration of ICU stay and survival. However, there was a significant reduction in the need for midazolam (used for spasms uncontrolled with high dose diazepam) and the neuromuscular blocking drug pipecuronium in the magnesium group. The need to use verapamil to terminate a tachycardia was also less likely in the group receiving magnesium. In a separate analysis, the same authors demonstrated that urinary adrenaline excretion was less and urinary noradrenaline secretion was higher in those receiving magnesium compared to placebo [33]. Clinical autonomic dysfunction was significantly associated with higher urinary adrenaline excretion, which magnesium seemed to protect against (noradrenaline excretion did not show a similar correlation with clinical autonomic dysfunction). Autonomic dysfunction in tetanus is known to be associated with a higher rate of catecholamine release, especially that of adrenaline [34]. It is plausible that magnesium exerts some of its beneficial effects by blocking adrenaline release. Two other trials, by Ali and colleagues [35] and Osalusi and colleagues [36] compared magnesium with diazepam for spasm control and showed conflicting results. A meta-analysis of all three trials showed that magnesium did not reduce mortality in tetanus [37].

Overall, from the available evidence it can be assumed that magnesium does have a therapeutic benefit in controlling muscle spasms and reducing autonomic instability. The randomized controlled trial that compared magnesium against placebo failed to demonstrate a benefit in reducing the need for ventilatory support and improving mortality rates [21]. Still, by nature of the study design, they were not able to incrementally titrate the magnesium dose according to patients' clinical picture and hence the overall serum magnesium concentrations achieved ( 2 to $2.5 \mathrm{mmol} / \mathrm{l}$ ) were in the lower range of the therapeutic range achieved by Attygalle and Rodrigo [31] (2 to $4 \mathrm{mmol} / \mathrm{l})$. Therefore, the conclusion by Thwaites and colleagues [21] that magnesium infusion was safe to be administered in facilities without ventilatory support cannot be entertained, especially if a model of administration of titrating to control symptoms (as done by Attygalle and Rodrigo) is followed [31]. In addition, the trial of Thwaites and colleagues gave magnesium sulfate for only 7 days while the duration of treatment was much longer in the uncontrolled case series. The effect of longer duration magnesium sulfate is therefore as yet unexplored in a randomized trial. Magnesium sulfate remains a relatively inexpensive treatment option to control muscle spasms and autonomic dysfunction in tetanus [38]. However, it alone may not be sufficient to control spasms in severe disease. It also needs frequent clinical and laboratory monitoring to avoid toxicity and has no effect on mortality.

\section{Intrathecal baclofen}

Baclofen is a GABA-B receptor agonist. Oral baclofen is thought to have poor penetration across the blood-brain barrier and hence is ineffective in tetanus [39]. However, intrathecal administration is shown to abolish spasms promptly. Muller and colleagues [40] demonstrated the efficacy of intrathecal baclofen in controlling severe spasms in tetanus, reducing the need for ventilation. However, the technique employed required baclofen to be delivered via a tunneled intrathecal catheter and a subcutaneous reservoir, which is prohibitively expensive in many resource-limited settings. Many reports on the efficacy of baclofen are limited to case reports of either one or a few patients, but so far there are more than 30 case reports in the published literature [41-50]. Boots and colleagues [42] treated two patients using a similar mechanism to deliver the drug and noted a reduction in the need for sedation and paralysis. Brock and colleagues [51] also note that baclofen alone was an effective measure in promptly abolishing prolonged muscle spasms at a dose of $850 \mu \mathrm{g} /$ day delivered via an intrathecal infusion pump. In the largest case series of patients treated with baclofen via an intrathecal infusion catheter, the drug was effective in controlling spasms in all but one patient $(\mathrm{n}=22)$ [52]. However, only three patients maintained spontaneous ventilation during the course of illness and all others required ventilatory support. The survival rate in this series was 95\%. Saissy and colleagues [47] assessed the efficacy of treating severe tetanus with intermittent intrathecal injections of baclofen rather than using a continuous infusion topped up with boluses. The argument was to assess the efficacy of an inexpensive measure of administration that can be utilized in resource-limited settings. In nine patients out of ten, the first injection itself resolved the spasms completely though the recovery of muscle rigidity was incomplete. However, five patients developed respiratory depression later on, of whom three needed ventilatory support. Overall, five patients had to be ventilated during the course of illness. Four patients were treated with baclofen exclusively. The survival rate in this series was $50 \%$.

The evidence base for baclofen is far smaller than that for magnesium sulfate. It is noted that the daily baclofen dose infused ranged from 500 to 2,000 $\mu \mathrm{g}$ in many of these case reports. At these doses, respiratory depression as well as cardiovascular instability were observed. Therefore, intrathecal administration of baclofen cannot be recommended without ICU and ventilatory facilities. 
While in many patients the initial loading dose and infusions were effective in relieving spasms, rigidity was not completely abolished. Some authors report incomplete resolution of symptoms even with high doses of baclofen, thus reflecting a patient-dependent variation in response [50,53]. One advantage in those responding to baclofen is the relatively longer duration of action and the need for less sedative drugs. However, the method of administration by an intrathecal pump is too expensive a measure to be employed in resourcelimited settings, and has the added disadvantage of being a potential route for secondary central nervous system infection [52]. Therefore, intrathecal baclofen infusion cannot be recommended as per current evidence as a standard treatment practice in resourcelimited settings.

\section{Other measures used for sedation and control of autonomic dysfunction}

Dantrolene is a muscle relaxant that is effectively used in the treatment of malignant hyperthermia and neuroleptic malignant syndrome. Checketts and White [54] report two patients with severe tetanus managed with dantrolene infusions (for muscle relaxation) and concurrent diazepam/midazolam infusions (for sedation) during the entire course of illness with subsequent recovery. Neither patient required artificial ventilation. Other case reports on the use of dantrolene are for milder grades of tetanus and demonstrate a successful outcome [55-57]. The use of ketamine along with intravenous diazepam is reported in one case report [58].

Successful use of botulinum toxin A for localized muscle spasms has also been reported. García-García and colleagues [59] used it to treat residual contractures of a woman recovering from cephalic tetanus and Herrman and colleagues [60] used it to treat painful trismus in a woman with localized tetanus. On both occasions, successful outcomes were observed, avoiding the need for systemic sedatives and muscle relaxants.

Bhagwanjee and colleagues [23] assessed the role of epidural blockade with bupivacaine and sufentanil in controlling the sympathetic hyperactivity in 11 patients with severe tetanus. Midazolam was used as the major sedative in all patients. Blood pressure fluctuations reduced significantly $(P<0.0001)$ from an average difference between the mean maximum and mean minimum systolic blood pressure of 78 ( $\mathrm{SD} \pm 28) \mathrm{mmHg}$ to 38 $(\mathrm{SD} \pm 15) \mathrm{mmHg}$ after epidural blockade. There was a non-significant reduction in heart rate fluctuations as well. The observations in this regard have not been investigated by others.

In another interesting approach to tackle autonomic instability, intravenous clonidine (an $\alpha 2$ adrenoreceptor agonist) was administered to 17 patients with severe tetanus and compared with 10 patients who did not receive clonidine [61]. Both groups received the same treatment otherwise. Blood pressure fluctuations were minimized with 3 days of clonidine administration and this group had a significantly lower mortality rate than the group not receiving clonidine. Dolar in 1992 [62] reported four patients managed with continuous atropine infusions in addition to standard therapy. The authors argue that although autonomic disturbance is widely accepted to be due to sympathetic overdrive, it may also be due to acetylcholine toxicity. There was one death in the series due to an unrelated cause and the other three patients survived. Though blood pressure fluctuations did stabilize in two patients after atropine use, it is difficult to gauge a direct therapeutic benefit as this was not a controlled trial. Dexmedetomidine, another $\alpha 2$ adrenoreceptor agonist with sedative effects (and minimal respiratory depression), was used to treat six patients with tetanus over 7 days as an infusion. Though it did not completely abolish muscle spasms and rigidity, it managed to reduce the need for other sedatives and muscle relaxants [63].

One of the earliest drugs used to try to tackle the sympathetic overdrive in tetanus was labetolol [64]. There are several case reports of labetolol being successfully used to treat adrenergic crises in tetanus characterized by tachycardia and hypertension [65,66]. In one case series of 15 patients, labetolol reduced tachycardia and blood pressure, but heart rate and blood pressure variability did not improve [67]. In some instances labetolol had to be co-administered with other drugs such as clonidine for a complete response [68]. Successful use of other beta blockers such as esmolol has also been described in the literature as case reports [69].

Intravenous morphine is another option to counter autonomic hyperactivity in tetanus. In a series of ten patients, intravenous infusion of morphine successfully controlled signs of autonomic dysfunction without the need for adrenergic blockers [70]. Part of this effect may be due to the analgesic effect of morphine reducing anxiety. Other authors have also observed the efficacy of morphine in this regard and some have attempted different routes of administration, such as intrathecal administration $[71,72]$.

Vitamin $C$ has been shown to reduce mortality from tetanus in animal studies. A single unblinded controlled trial (presumably non-randomized) conducted in 1980 by Jahan and colleagues [73] showed a significant reduction in mortality in adults and children receiving a daily dose of $1 \mathrm{~g}$ intravenous vitamin $\mathrm{C}$ as adjunctive therapy. The methodological flaws in this trial and lack of confirmation of the results in other studies make it difficult to comment on this observation [74]. 


\section{Neutralization of toxin: route of administration of immunoglobulins}

Administration of human antitetanus immunoglobulin (HTIg) or equine antitetanus serum is an established practice in the treatment of tetanus. Since the damage caused by tetanospasmin that has entered the nervous system is irreversible, much emphasis is placed on neutralizing the circulating toxin before it enters the nervous system. Many authors have explored whether administering these immunoglobulins intrathecally (rather than the traditional intramuscular injections) would have an additional benefit.

Sun and colleagues [75] report a non-randomized controlled unblinded trial where 9 patients out of 17 with tetanus of varying severity received $250 \mathrm{IU}$ of intrathecal HTIg as adjunctive therapy. Both groups were comparable in severity of disease, age group and other treatments received, including HTIg via the standard route (to all patients). The observed mortality rate was significantly less for the group receiving intrathecal therapy and the total duration of ICU stay and the hospital stay was also less though did not differ significantly from the control group.

One of the largest trials in this regard was conducted by Miranda-Filho and colleagues [76], who randomly assigned patients to two groups to receive either intramuscular HTIg (3,000 IU) plus intrathecal HTIg (1,000 IU) or intramuscular HTIg alone. The rest of the treatment protocols were similar for both groups. While there was no significant difference in mortality rates, need for mechanical ventilation or occurrence of complications, a statistically significant improvement was observed in the treatment group with regard to improvement of spasms and reduction in hospital stay. A similar observation of a shorter hospital stay (plus a significant mortality benefit) was made by Ahmad and colleagues [77], who conducted a non-blinded controlled trial administering intrathecal HTIg (study group) versus standard therapy (control group) for neonatal tetanus. In a retrospective analysis of 66 patients who were administered HTIg intrathecally, Geeta and colleagues [78] concluded that complications were less compared to other centers where immunoglobulin was administered intramuscularly.

While many of the studies mentioned above favor intrathecal administration of human immunoglobulin, the evidence for its benefit is not concrete. Many confounding factors might have led to a better outcome rather than the intrathecal administration of immunoglobulins itself. Two Cochrane reviews on the subject have found conflicting results in this regard. The analysis by Abrutyn and Berlin [79] does not recommend the intrathecal use of either human immunoglobulin or equine antitetanus serum unless in the context of a randomized clinical trial. A later metanalysis by Kabura and colleagues [80], however, concluded that intrathecal immunoglobulin or antitetanus serum administration is preferable to standard intramuscular administration. When opting for intrathecal administration of immunoglobulins, the clinician must also take into account the rare but reported adverse event of reversible paraplegia [81].

Tetanus infection does not induce immunity; therefore, active immunization is also recommended for a patient as part of treatment. The tetanus toxoid should be given at a separate site from immunoglobulin administration. Those who have not had active immunization before will need another two booster doses within 1 year of the first dose.

\section{Antibiotics in tetanus}

Antibiotics are administered to patients with tetanus on the presumption that it prevents local proliferation of $C$. tetani at the wound site. The antibiotics that can be used include penicillin G, metronidazole and doxycycline. However, although resistance is rare, the bacteria may not be universally sensitive to the first-line antibiotics in tetanus. An analysis of microbiological susceptibility of C. tetani isolated from wounds of patients diagnosed with tetanus showed that initially all were susceptible to penicillin and metronidazole. After treating with high dose penicillin, however, two isolates were found to be penicillin-resistant 16 days later [82]. While these findings cannot be applied universally due to various local resistance patterns of bacteria, it nevertheless stresses the need for repeated sensitivity testing during treatment.

While penicillin and metronidazole are both recommended in treating tetanus, some argue that metronidazole may be a better option. This is based on the fact that penicillin produces a non-competitive voltagedependent inhibition of GABA-A receptors obtunding post-synaptic inhibitory potentials. In this regard, penicillin in large doses is known to cause seizures and many have proposed a theoretical possibility of potentiating the action of tetanospasmin. If such an effect exists, it becomes a serious issue as there is no solid evidence for a benefit of antibiotic therapy itself in tetanus. The question remains whether, in that case, penicillin administration may do more harm than good. A trial by Ahmadsyah and Salim [83] demonstrated a mortality benefit for patients treated with metronidazole compared to penicillin as far back as 1985. Based on these data, many experts recommended metronidazole over penicillin $[84,85]$. Later, in a randomized controlled trial in India, Ganesh Kumar and colleagues [86] assessed outcome after three different antibiotic preparations were given to 161 patients with tetanus. These were 
benzathine penicillin (1.2 million units as a single dose intramuscularly; $n=56)$, intravenous benzyl penicillin ( 2 million units every 4 hours for 10 days; $n=50$ ) and oral metronidazole $(600 \mathrm{mg}$ every 6 hours for 10 days; $\mathrm{n}=$ $55)$. While the three arms were similar in age distribution, sex and severity of tetanus score according to Ablett criteria, no significant difference in outcome was observed in relation to the duration of hospital stay, need for mechanical ventilation, need for neuromuscular blockade and concurrent respiratory tract infections.

\section{Limitations}

Several 'standard' management strategies for tetanus, such as using benzodiazepines and antibiotics, are not evidence based. However, given their theoretical importance of use, designing clinical trials to evaluate their efficacy against placebo is unethical. Many treatment options mentioned above have not been assessed with randomized controlled trials and it is becoming increasingly difficult to do so given the rarity of the illness. In the few developing resource-limited settings where

Table 1 Summary of evidence base for treatment modalities used in tetanus

\begin{tabular}{|c|c|c|c|}
\hline $\begin{array}{l}\text { Treatment } \\
\text { modality }\end{array}$ & Advantages and disadvantages & $\begin{array}{l}\text { Summary of findings and } \\
\text { level of evidence }\end{array}$ & Recommendation \\
\hline \multicolumn{4}{|l|}{$\begin{array}{l}\text { Relief of muscle } \\
\text { spasms }\end{array}$} \\
\hline \multirow[t]{3}{*}{ Benzodiazepines } & $\begin{array}{l}\text { Advantages: combined sedative, anticonvulsant } \\
\text { and muscle relaxant effects }\end{array}$ & Used as standard therapy & \multirow[t]{3}{*}{$\begin{array}{l}\text { Expert opinion favors use; } \\
\text { standard of care }\end{array}$} \\
\hline & Readily available & $\begin{array}{l}\text { A meta-analysis comparing against less } \\
\text { used options nowadays showed no } \\
\text { benefit in using diazepam }\end{array}$ & \\
\hline & $\begin{array}{l}\text { Disadvantages: prolonged duration of action } \\
\text { with long-acting drugs }\end{array}$ & $\begin{array}{l}\text { Ethical issues may prevent designing of } \\
\text { trials to test efficacy }\end{array}$ & \\
\hline \multirow[t]{5}{*}{ Magnesium sulfate } & $\begin{array}{l}\text { Advantages: readily available in resource-limited } \\
\text { settings }\end{array}$ & $\begin{array}{l}\text { Meta-analysis shows no mortality } \\
\text { benefit (level of evidence A) }\end{array}$ & \multirow{5}{*}{$\begin{array}{l}\text { Use may be reasonable and } \\
\text { should be considered depending } \\
\text { on clinician judgment }\end{array}$} \\
\hline & Has anticonvulsant, muscle relaxant properties & \multirow{4}{*}{$\begin{array}{l}\text { Inadequate evidence to decide on a } \\
\text { positive impact on ICU/hospital stay }\end{array}$} & \\
\hline & Disadvantages: needs close monitoring & & \\
\hline & Risk of hypocalcaemia & & \\
\hline & Less effective in severe disease & & \\
\hline \multirow[t]{2}{*}{ Intrathecal baclofen } & Advantages: abolishes spasms promptly & \multirow{2}{*}{$\begin{array}{l}\text { Evidence is limited to a few case series } \\
\text { (level of evidence C) }\end{array}$} & \multirow{2}{*}{$\begin{array}{l}\text { May be harmful in settings where } \\
\text { sterility and proper monitoring } \\
\text { cannot be maintained }\end{array}$} \\
\hline & $\begin{array}{l}\text { Disadvantages: risk of central nervous system } \\
\text { infections High cost }\end{array}$ & & \\
\hline $\begin{array}{l}\text { Dantrolene, } \\
\text { ketamine, propofol, } \\
\text { botulinum toxin }\end{array}$ & & $\begin{array}{l}\text { Benefit observed in some case reports } \\
\text { only (level of evidence C) }\end{array}$ & $\begin{array}{l}\text { Cannot be recommended without } \\
\text { further evidence }\end{array}$ \\
\hline \multicolumn{4}{|l|}{$\begin{array}{l}\text { Reducing } \\
\text { autonomic } \\
\text { instability }\end{array}$} \\
\hline \multirow[t]{2}{*}{$\begin{array}{l}\text { Clonidine, } \\
\text { morphine, } \\
\text { bupivacaine with } \\
\text { sufentanil, labetolol }\end{array}$} & $\begin{array}{l}\text { Advantages: reduces tachycardia and systolic } \\
\text { blood pressure fluctuations. The sedative effect } \\
\text { of morphine reduces anxiety and cardiovascular } \\
\text { instability }\end{array}$ & \multirow[t]{2}{*}{$\begin{array}{l}\text { Evidence limited to case reports and } \\
\text { few case series (level of evidence C) }\end{array}$} & \multirow[t]{2}{*}{$\begin{array}{l}\text { Use may be reasonable on a case } \\
\text { by case basis }\end{array}$} \\
\hline & $\begin{array}{l}\text { Disadvantages: beta blockers can worsen } \\
\text { hypotension, bradycardia }\end{array}$ & & \\
\hline $\begin{array}{l}\text { Administration of } \\
\text { immunoglobulins }\end{array}$ & $\begin{array}{l}\text { Administration of immunoglobulins is beneficial. } \\
\text { The best route of administration (intramuscular } \\
\text { alone versus intrathecal plus intramuscular) is } \\
\text { debated }\end{array}$ & $\begin{array}{l}\text { Evidence from two meta-analyses are } \\
\text { conflicting }\end{array}$ & $\begin{array}{l}\text { Intrathecal administration of } \\
\text { immunoglobulins (in addition to } \\
\text { intramuscular administration) may } \\
\text { be beneficial }\end{array}$ \\
\hline \multirow[t]{2}{*}{ Use of antibiotics } & \multirow{2}{*}{$\begin{array}{l}\text { Metronidazole use has a theoretical advantage } \\
\text { over penicillin use as the latter can potentially } \\
\text { facilitate tetanospasmin activity }\end{array}$} & $\begin{array}{l}\text { There are no trials to suggest that } \\
\text { antibiotic use is beneficial in tetanus }\end{array}$ & \multirow{2}{*}{$\begin{array}{l}\text { Either penicillin or metronidazole } \\
\text { may be used as the antibiotic of } \\
\text { choice in treating tetanus (expert } \\
\text { opinion) }\end{array}$} \\
\hline & & $\begin{array}{l}\text { Evidence from a randomized controlled } \\
\text { trial shows no benefit of choosing } \\
\text { metronidazole over penicillin (level of } \\
\text { evidence B) }\end{array}$ & \\
\hline
\end{tabular}


tetanus still occurs at a high frequency, infrastructure and technical expertise to carry out clinical trials are not available. Some expensive treatment strategies, such as intrathecal baclofen, are out of reach for researchers in such settings and may even be harmful for patients if sterility cannot be maintained in a controlled environment. The efficacy of different treatment modalities also depends on the severity of disease in each patient. For a comparison of patients between studies, there should be a uniform scoring system to assess severity of disease. Different studies have used various measures to assess severity and others have not commented on it at all, which makes it difficult to objectively assess the therapeutic efficacy for each option.

\section{Conclusions}

The traditional management strategy in tetanus involves sedation, neuromuscular paralysis and elective ventilation combined with wound debridement, antibiotic therapy and administration of HTIg (or equine antitetanus serum) to neutralize the toxin. Due to the associated complications of prolonged ventilation, many have searched for ways of reducing the need for paralysis and elective ventilation. The evidence base for these practices is as follows (a detailed summary of these recommendations is given in Table 1).

Despite benzodiazepines being popular as standard therapy for sedation and reducing spasms, the evidence for their superiority over other options is lacking. However, this may be due to the difficulty and ethical issues in designing trials to evaluate their efficacy. Intravenous magnesium sulfate reduces muscle spasms and autonomic dysfunction but it may not be suitable as sole therapy to relieve spasms in severe tetanus and has no proven mortality benefit. Intrathecal baclofen is an effective option to relieve spasms till recovery but its use is limited due to costs and the risks of introducing concurrent central nervous system infection. Benefits reported with dantrolene, botulinum toxin (for local forms of spasms) in reducing muscle spasms and that of epidural blockade and clonidine to reduce autonomic dysfunction need to be further evaluated with controlled trials before being recommended as standard therapy.

The beneficial role of intrathecal HTIg or equine antitetanus sera is not well established. However, the majority of studies are in favor of intrathecal administration. The use of this mode of administration should be at the treating physician's discretion. Recommendations cannot be made for the exact dose for intrathecal administration.

The evidence base for the efficacy of antibiotics in tetanus is limited. Metronidazole and penicillin can be used as the bacterium is susceptible to both. There is a theoretical advantage of using metronidazole but its clinical correlations have not been well established by trials.

\section{Abbreviations}

HTIg: Human antitetanus immunoglobulin; IV: Intravenous; SD: Atandard deviation; WHO: World health organization.

\section{Competing interests}

The authors declare that they have no competing interests.

\section{Authors' contributions}

All authors have participated in designing, article search, information coding and writing of the manuscript. All authors have read and approved the final manuscript.

\section{Author details}

${ }^{1}$ Tropical Medicine Research Unit, Department of Clinical Medicine, Faculty of Medicine, University of Colombo, 25 Kynsey Road, Colombo 08, Sri Lanka.

${ }^{2}$ Department of Parasitology, Faculty of Medicine, University of Colombo, 25 Kynsey Road, Colombo 08, Sri Lanka.

\section{Published: 26 Mar 2014}

\section{References}

1. Chalya PL, Mabula JB, Dass RM, Mbelenge N, Mshana SE, Gilyoma JM: Ten-year experiences with tetanus at a tertiary hospital in Northwestern Tanzania: a retrospective review of 102 cases. World J Emerg Surg 2011, 6:20.

2. Brauner JS, Vieira SR, Bleck TP: Changes in severe accidental tetanus mortality in the ICU during two decades in Brazil. Intensive Care Med 2002, 28:930-935.

3. Joshi S, Agarwal B, Malla G, Karmacharya B: Complete elimination of tetanus is still elusive in developing countries: a review of adult tetanus cases from referral hospital in Eastern Nepal. Kathmandu Univ Med J 2007, 5:378-381.

4. Chukwubike OA, God'spower AE: A 10-year review of outcome of management of tetanus in adults at a Nigerian tertiary hospital. Ann Afr Med 2009, 8:168-172.

5. Center for Disease Control: Tetanus surveillance - United States, 2001-2008. MMWR 2011, 60:365-369.

6. Chaudhry R, Dhawan B, Mohanty S, Dey AB: Tetanus in the elderly: a forgotten illness. Lancet 1805, 2001:357.

7. Immunization surveillance, assessment and monitoring: tetanus. http://www. who.int/immunization_monitoring/diseases/tetanus/en/index.html.

8. Maternal and Neonatal Tetanus (MNT) elimination: the initiative and challenges. http://www.who.int/immunization_monitoring/diseases/ MNTE_initiative/en/.

9. Maternal and Neonatal Tetanus (MNT) elimination: progress towards global MNT elimination. http://www.who.int/immunization_monitoring/diseases/ MNTE_initiative/en/index4.html.

10. Abrutyn E: Tetanus. In Harrison's Principles of Internal Medicine. 14th edition. Edited by Isselbacher KL, Braunwald E, Wilson JD, Martin JB, Fauci AS, Kasper DL, Longo DL, Hauser SL. New York: McGraw Hill; 1998:901-904.

11. Gilligan JE, Lawrence JR, Clayton D, Rowland R: Tetanus and the evolution of intensive care in Australia. Crit Care Resusc 2012, 14:316-323.

12. Chun P, Ying-Zi H, Yi Y, Hai-Bo Q: Titration of high dose sedation is effective in severe tetanus: a case report. Cases J 2009, 2:6865.

13. Firth PG, Solomon JB, Roberts LL, Gleeson TD: Airway management of tetanus after the Haitian earthquake: new aspects of old observations. Anesth Analg 2011, 113:545-547.

14. Petitjeans F, Turc J, Coulet O, Puidupin M, Eve O, Benois A: The use of boluses of propofol for the management of severe tetanus in a child. Trop Doct 2009, 39:52-53.

15. Norredam K, Hainau B: Treatment of tetanus in tropical Africa: a comparison between a barbiturate and diazepam in the treatment of non-neonatal tetanus. Ann Soc Belges Med Trop Parasitol Mycol 1970, 50:239-246

16. Joseph A, Pulimood BM: Use of diazepam in tetanus - a comparative study. Indian J Med Res 1978, 68:489-491. 
17. Okoromah CN, Lesi FE: Diazepam for treating tetanus. Cochrane Database Syst Rev 2004, CD003954

18. Orko R, Rosenberg PH, Himberg JJ: Intravenous infusion of midazolam, propofol and vecuronium in a patient with severe tetanus. Acta Anaesthesiol Scand 1988, 32:590-592.

19. Peduto VA, Pisanu GM, Piga M: Midazolam, propofol, and clonidine for sedation and control of autonomic dysfunction in severe generalized tetanus. Minerva Anestesiol 1993, 59:171-178.

20. Guzman JA, Guerrero A, Lopez-Obispo M, Artacho R, de la Cruz JIG, Alemany F, Sanchez-Lopez F: Continuous perfusion with midazolam and atracurium in a patient with severe tetanus. Rev Esp Anestesiol Reanim 1993, 40:375.

21. Thwaites CL, Yen LM, Loan HT, Thuy TT, Thwaites GE, Stepniewska K, Soni N, White NJ, Farrar JJ: Magnesium sulphate for treatment of severe tetanus: a randomised controlled trial. Lancet 2006, 368:1436-1443.

22. Gyasi HK, Fahr J, Kurian E, Mathew M: Midazolam for prolonged intravenous sedation in patients with tetanus. Middle East J Anesthesiol 1993, 12:135-141.

23. Bhagwanjee S, Bosenberg AT, Muckart DJ: Management of sympathetic overactivity in tetanus with epidural bupivacaine and sufentanil: experience with 11 patients. Crit Care Med 1999, 27:1721-1725.

24. Hahn BJ, Erogul M, Sinert R: Case report of tetanus in an immunized, healthy adult and no point of entry. J Emerg Med 2004, 27:257-260.

25. Bunch TJ, Thalji MK, Pellikka PA, Aksamit TR: Respiratory failure in tetanus: case report and review of a 25-year experience. Chest 2002, 122:1488-1492.

26. Karanikolas M, Velissaris D, Marangos M, Karamouzos V, Fligou F, Filos KS: Prolonged high-dose intravenous magnesium therapy for severe tetanus in the intensive care unit: a case series. J Med Case Reports 2010, 4:100.

27. Mathew PJ, Samra T, Wig J: Magnesium sulphate for treatment of tetanus in adults. Anaesth Intensive Care 2010, 38:185-189.

28. The Eclampsia Trial Collaborative Group: Which anticonvulsant for women with eclampsia? Evidence from the Collaborative Eclampsia Trial. Lancet 1995, 345:1455-1463.

29. Blake JA: The use of magnesium sulphate in the production of anaesthesia and in the treatment of tetanus. Surg Gynecol Obstetrics 1906, 2:541-550.

30. James MFM, Manson EDM: The use of magnesium sulphate infusions in the management of very severe tetanus. Intensive Care Med 1985, 11:5-12.

31. Attygalle $D$, Rodrigo N: Magnesium as first line therapy in the management of tetanus: a prospective study of 40 patients. Anaesthesia 2002, 57:811-817.

32. Attygalle $D$ : Magnesium sulphate in the management of severe tetanus averts artificial ventilation and sedation. Ceylon Med J 1996, 41:120.

33. Thwaites $\mathrm{CL}$, Yen LM, Cordon SM, Thwaites GE, Loan HT, Thuy TT, White NJ, Soni N, Macdonald IA, Farrar JJ: Effect of magnesium sulphate on urinary catecholamine excretion in severe tetanus. Anaesthesia 2008, 63:719-725.

34. Thwaites CL, Yen LM, Cordon SM, Binh NTTN, Nga N, White NJ, Soni N, MacDonald IA, Farrar JJ: Urinary catecholamine excretion in tetanus. Anaesthesia 2006, 61:355-359.

35. Ali G, Kamal M, Khan AN: Comparison of the efficacy of magnesium sulphate and diazepam in the control of tetanus spasm. J Postgraduate Med Inst 2011, 25:106-110.

36. Osalusi BS, Ogun SA, Ogunniyi A, Kolapo KO: Comparison of the efficacy of magnessium sulphate and diazepam in the control of tetanus spasms. Sci Res Essays 2008, 3:571-576.

37. Rodrigo C, Samarakoon L, Fernando D, Rajapakse S: A meta-analysis of magnesium for tetanus. Anaesthesia 2012, 67:1370-1374.

38. Attygalle $\mathrm{D}$, Rodrigo $\mathrm{N}$ : New trends in the management of tetanus. Expert Rev Anti Infect Ther 2004, 2:73-84.

39. Deibert E, Bhardwaj A, Staats PS, Ulatowski JA: Chronic intrathecal baclofen administration for the treatment of severe generalized tetanus via a synchromed infusion pump. Neuromodulation 1998, 1:2-5.

40. Muller $\mathrm{H}$, Borner $\mathrm{U}$, Zierski J, Hempelmann G: Intrathecal baclofen for treatment of tetanus-induced spasticity. Anesthesiology 1987, 66:76-79.

41. Pellanda A, Caldiroli D, Vaghi GM, Bonelli S: Treatment of severe tetanus by intrathecal infusion of baclofen. Intensive Care Med 1993, 19:59.

42. Boots RJ, Lipman J, O'Callaghan J, Scott P, Fraser J: The treatment of tetanus with intrathecal baclofen. Anaesth Intensive Care 2000, 28:438-442.

43. Saissy JM, Demaziere J, Vitris M, Seck M, Marcoux L, Gaye M, Ndiaye M: Treatment of severe tetanus by intrathecal injections of baclofen without artificial ventilation. Intensive Care Med 1992, 18:241-244.
44. Cabrerizo Garcia JL, Homs Gimeno CA, Pacheco Arancibia G, Zalba Etayo B, Sanchez Marteles M: Treatment of tetanus with intrathecal baclofen. An Med Interna 2008, 25:372-373.

45. Engrand N, Vilain G, Rouamba A, Benhamou D: Value of intrathecal baclofen in the treatment of severe tetanus in the tropical milieu. Med Trop (Mars) 2000, 60:385-388

46. Francois B, Clavel M, Desachy A, Vignon P, Salle JY, Gastinne H: Continuous intrathecal injection of baclofen in generalized tetanus. A therapeutic alternative. Presse Med 1997, 26:1045-1047.

47. Saissy JM, Raux O, Gohard R, Diatta B: Severe tetanus and intrathecal baclofen. Ann Fr Anesth Reanim 1990, 9:183-184.

48. Vitris M, Saissy JM, Demaziere J, Seck M, Ndiaye M, Gaye N, Marcoux L: Treatment of severe tetanus by repeated intrathecal injections of baclofen. Dakar Med 1991, 36:28-29.

49. Solsona M, Miro G, Yebenes JC, Balanzo X, Almirall J, Mauri M: Tetanus treated with continuous baclofen intrathecal perfusion]. Med Intensiva 2007, 31:204-206.

50. Dressnandt J, Konstanzer A, Weinzierl FX, Pfab R, Klingelhofer J: Intrathecal baclofen in tetanus: four cases and a review of reported cases. Intensive Care Med 1997, 23:896-902.

51. Brock H, Moosbauer W, Gabriel C, Necek S, Bidal D: Treatment of severe tetanus by continuous intrathecal infusion of baclofen. I Neurol Neurosurg Psychiatry 1995, 59:193-194.

52. Santos ML, Mota-Miranda A, Alves-Pereira A, Gomes A, Correia J, Marcal N: Intrathecal baclofen for the treatment of tetanus. Clin Infect Dis 2004, 38:321-328

53. Thomas RM, Bellamy MC: Tetanus in a subcutaneous drug abuser: ineffectiveness of intrathecal baclofen. Anaesth Intensive Care 2006 34:811-815.

54. Checketts MR, White RJ: Avoidance of intermittent positive pressure ventilation in tetanus with dantrolene therapy. Anaesthesia 1993, 48:969-971.

55. Ortega Cerda JJ, Portela Ortiz JM, Ramirez Acosta J: Successful treatment of tetanus with dantrolene (author's transl). Rev Invest Clin 1981, 33:53-55.

56. Sternlo JE, Andersen LW: Early treatment of mild tetanus with dantrolene. Intensive Care Med 1990, 16:345-346.

57. Rocha H: Myo-relaxant action of sodium dantrolene in the treatment of tetanus. Rev Inst Med Trop Sao Paulo 1975, 17:257-262.

58. Obanor $\mathrm{O}$, Osazuwa $\mathrm{HO}$, Amadasun JE: Ketamine in the management of generalised cephalic tetanus. J Laryngol Otol 2008, 122:1389-1391.

59. García-García A, Gandara-Rey JM, Crespo-Abelleira A, Jorge-Barreiro J: Botulinum toxin A for treating muscular contractures in cephalic tetanus. Br J Oral Maxillofac Surg 2007, 45:573-575.

60. Herrman H, Braekhus A, Aaserud O, Aukrust P, Stubhaug A, Hassel B: Early treatment of tetanus-induced trismus with botulinum toxin $A$. Anesth Analg 2008, 106:1591.

61. Gregorakos L, Kerezoudi E, Dimopoulos G, Thomaides T: Management of blood pressure instability in severe tetanus: the use of clonidine. Intensive Care Med 1997, 23:893-895.

62. Dolar D: The use of continuous atropine infusion in the management of severe tetanus. Intensive Care Med 1992, 18:26-31.

63. Girgin NK, Iscimen R, Gurbet A, Kahveci F, Kutlay O: Dexmedetomidine sedation for the treatment of tetanus in the intensive care unit. $\mathrm{Br} J$ Anaesth 2007, 99:599-600.

64. Dundee JW, Morrow WF: Labetalol in severe tetanus. Br Med J 1979, 1:1121-1122.

65. Domenighetti GM, Savary G, Stricker H: Hyperadrenergic syndrome in severe tetanus: extreme rise in catecholamines responsive to labetalol. Br Med J (Clin Res Ed) 1984, 288:1483-1484.

66. Hanna W, Grell GA: Oral labetalol in the management of the sympathetic overactivity of severe tetanus. South Med J 1980, 73:653-654.

67. Wesley AG, Hariparsad D, Pather M, Rocke DA: Labetalol in tetanus, The treatment of sympathetic nervous system overactivity. Anaesthesia 1983, 38:243-249.

68. Esslinger $\mathrm{P}$, Kistler W, Berger TM: Severe autonomic dysfunction in an 11year-old girl with generalised tetanus. Eur J Pediatr Surg 2003, 13:209-212.

69. Beards SC, Lipman J, Bothma PA, Joynt GM: Esmolol in a case of severe tetanus. Adequate haemodynamic control achieved despite markedly elevated catecholamine levels. S Afr J Surg 1994, 32:33-35.

70. Rocke DA, Wesley AG, Pather M, Calver AD, Hariparsad D: Morphine in tetanus - the management of sympathetic nervous system overactivity. S Afr Med J 1986, 70:666-668. 
71. Buchanan N, Cane RD, Wolfson G, De Andrade M: Autonomic dysfunction in tetanus: the effects of a variety of therapeutic agents, with special reference to morphine. Intensive Care Med 1979, 5:65-68.

72. Sun S, Dolar D, Ozenc E: Intrathecal morphine in tetanus. Br J Anaesth 1982, 54:699-700.

73. Jahan K, Ahmad K, Ali MA: Effect of ascorbic acid in the treatment of tetanus. Bangladesh Med Res Counc Bull 1984, 10:24-28.

74. Hemila H, Koivula TT: Vitamin C for preventing and treating tetanus. Cochrane Database Syst Rev 2008, CD006665.

75. Sun KO, Chan YW, Cheung RT, So PC, Yu YL, Li PC: Management of tetanus: a review of 18 cases. J R Soc Med 1994, 87:135-137.

76. Miranda-Filho Dde B, Ximenes RA, Barone AA, Vaz VL, Vieira AG, Albuquerque VM: Randomised controlled trial of tetanus treatment with antitetanus immunoglobulin by the intrathecal or intramuscular route. BMJ 2004, 328:615.

77. Ahmad A, Qaisar I, Naeem M, Mazhar AU, Ashfaq M: Intrathecal antitetanus human immunoglobulin in the treatment of neonatal tetanus. J Coll Physicians Surg Pak 2011, 21:539-541.

78. Geeta MG, Krishnakumar P, Mathews L: Intrathecal tetanus immunoglobulins in the management of tetanus. Indian J Pediatr 2007, 74:43-45.

79. Abrutyn E, Berlin JA: Intrathecal therapy in tetanus, A meta-analysis. JAMA 1991, 266:2262-2267.

80. Kabura L, llibagiza D, Menten J, Van den Ende J: Intrathecal vs. intramuscular administration of human antitetanus immunoglobulin or equine tetanus antitoxin in the treatment of tetanus: a meta-analysis. Trop Med Int Health 2006, 11:1075-1081.

81. Robert R, Rouffineau J, Cremault A, Bauple JL, Pourrat O, Gil R, Patte D: Reversible paraplegia following intrathecal injection of high doses of human gammaglobulins in the treatment of low-grade tetanus. Four cases. Presse Med 1984, 13:1947-1949.

82. Campbell II, Lam TM, Huynh TL, To SD, Tran TT, Nguyen VM, Le TS, Nguyen W, Parry C, Farrar JJ, Tran TH, Baker S: Microbiologic characterization and antimicrobial susceptibility of Clostridium tetani isolated from wounds of patients with clinically diagnosed tetanus. Am J Trop Med Hyg 2009, 80:827-831.

83. Ahmadsyah I, Salim A: Treatment of tetanus: an open study to compare the efficacy of procaine penicillin and metronidazole. Br Med J (Clin Res Ed) 1985, 291:648-650.

84. Cook TM, Protheroe RT, Handel JM: Tetanus: a review of literature. $\mathrm{Br} J$ Anaesth 2001, 87:477-487.

85. Farrar JJ, Yen LM, Cook T, Fairweather NF, Binh N, Parry J, Parry CM: Tetanus. J Neurol Neurosurg Psychiatry 2000, 69:292-301.

86. Ganesh Kumar AV, Kothari VM, Krishnan A, Karnad DR: Benzathine penicillin, metronidazole and benzyl penicillin in the treatment of tetanus: a randomized, controlled trial. Ann Trop Med Parasitol 2004, 98:59-63.

$10.1186 /$ cc13797

Cite this article as: Rodrigo et al: Pharmacological management of tetanus: an evidence-based review. Critical Care 2014, 18:217 